\title{
PENINGKATAN PENGETAHUAN TERHADAP BAHAYA LINGKUNGAN PADA SISWA DI SEKOLAH DASAR SAWARNA 1 KECAMATAN BAYAH KABUPATEN LEBAK PROVINSI BANTEN
}

\author{
Aris Munandar, Ode Sofyan Hardi, Rayuna Handawati \\ Program Studi Pendidikan Geografi Fakultas Ilmu Sosial Universitas Negeri Jakarta \\ amunandar@unj.ac.id, Ode-sofyan-hardi@unj.ac.id rhandawati@unj.ac.id
}

\begin{abstract}
Recognizing the dangers that threaten the environment for students is important because it can spread information to the environment in the school itself, spread to the home and community environment. Through socialization and simulation students are directly involved in the effort to recognize the dangers. The activity will be held on Friday September 14, 2019, 09.00 am - finished in Sawarna 1 Elementary School, Bayah District. Lebak The number of participants 35 students. Implementation activities were divided into 2 sessions, namely the delivery of material and simulations. Before the material is presented, the pretest is conducted, after the material is given a post-test. Submission of knowledge includes: the delivery of material, giving quizzes, games. Introduction of existing types of disasters, namely: earthquakes, tsunamis, landslides, floods, typhoons, fires, volcanoes erupt. The introduction of disaster types is important so that students get a correct understanding of the types of disasters that exist. The next material is about which locations should be addressed and avoided (fields, houses, buildings, beaches, plateaus, trees, rivers). In general, the evaluation results and simulation results can be run according to the objectives. Participants who are third-grade elementary school students can understand the types of disasters, disasters that may occur in their environment, can understand the destination when an earthquake or tsunami occurs. Students can mention the characteristics of a tsunami. Students can follow the simulation while singing. He hopes after getting the right understanding can be transmitted to other friends, as well as family and society in general. The absence of changes to the question about tsunamis is expected to be able to create other models and strategies, students have not yet correctly understood about the tsunami disaster. Broader socialization needs to be done through scout activities and others.
\end{abstract}

Keyword : disaster, simulation, knowledge, Sawarna

\begin{abstract}
Abstrak
Pengenalan bahaya yang mengancam lingkungan pada siswa menjadi penting karena dapat menyebarkan informasi kepada lingkungan di sekolah sendiri, menyebar kerumah dan lingkungan masyarakat. Melalui sosialisasi dan simulasi siswa terlibat langsung dalam usaha untuk mengenal bahaya. Kegiatan dilaksanakan pada hari jumat tanggal 14 September 2019, Jam 09.00- selesai di Ruang kelas SD Sawarna 1 Kecamatan Bayah Ka. Lebak. Jumlah peserta 35 siswa terdiri dari 20 siswi dan 15 siswa. Kegiatan pelaksanaan dibagi menjadi 2 sesi, yaitu penyampaian materi dan simulasi. Sebelum disampaikan materi dilakukan pretest, setelah penyampaian materi diberikan post-test. Penyampaian pengetahuan meliputi : penyampaian materi, memberikan kuis, permainan. Pengenalan jenis bencana yang ada yaitu : gempa bumi, tsunami, tanah longsor, banjir, angin putting beliung/topan, kebakaran, gunung meletus. Pengenalan jenis bencana penting agar siswa mendapatkan pemahaman yang benar tentang jenis bencana yang ada. Materi selanjutnya tentang lokasi mana yang harus dituju dan dihindari (lapangan, rumah, gedung, pantai, dataran tinggi, pohon, sungai).

Secara umum dari hasil evaluasi dan hasil simulasi dapat berjalan sesuai dengan tujuan. Peserta yang merupakan siswa sekolah dasar kelas tiga sekolah dapat memahami jenis bencana, bencana yang mungkin terjadi dilingkungannya, dapat memahami tempat yang dituju ketika terjadi gempa maupun tsunami. Siswa dapat menyebutkan ciri-ciri terjadinya tsunami. Siswa dapat mengikuti simulasi dengan sambil bernyanyi. Harapannya setelah mendapatkan pemahaman yang benar dapat ditularkan kepada teman-temannya yang lain, maupun keluarga dan masyarakat pada umumnya. Tidak adanya perubahan pada pertanyaan tentang tsunami diharapkan dapat membuat model dan strategi yang lain, siswa belum benar pemahaman tentang bencana tsunami. Perlu adanya sosialisasi yang lebih luas melalui kegiatan pramuka dan lain-lain.

Kata Kunci : Bencana, pengetahuan, simulasi, Sawarna
\end{abstract}




\section{PENDAHULUAN}

Letak Indonesia yang berada pada jalur pegunungan dan berbentuk kepulauan mempengaruhi kondisi alam baik yang menguntungkan ataupun mendatangkan kerugian. Kondisi yang merugikan yaitu adanya resiko bencana. Pada umumnya risiko bencana alam meliputi bencana akibat faktor geologi (gempabumi, tsunami dan letusan gunung api), bencana akibat hidrometeorologi (banjir, tanah longsor, kekeringan, angin topan), bencana akibat faktor biologi (wabah penyakit manusia, penyakit tanaman/ternak, hama tanaman) serta kegagalan teknologi (kecelakaan industri, kecelakaan transportasi, radiasi nuklir, pencemaran bahan kimia). Bencana akibat ulah manusia terkait dengan konflik antar manusia akibat perebutan sumberdaya yang terbatas, alasan ideologi, religius serta politik. Sedangkan kedaruratan kompleks merupakan kombinasi dari situasi bencana pada suatu daerah.

Bencana alam dapat terjadi secara tiba-tiba maupun melalui proses yang berlangsung secara perlahan. Beberapa jenis bencana seperti gempa bumi, hampir tidak mungkin diperkirakan secara akurat kapan, dimana akan terjadi dan besaran kekuatannya. Sedangkan beberapa bencana lainnya seperti banjir, tanah longsor, kekeringan, letusan gunung api, tsunami dan anomali cuaca masih dapat diramalkan sebelumnya. Meskipun demikian kejadian bencana selalu memberikan dampak kejutan dan menimbulkan banyak kerugian baik jiwa maupun materi. Kejutan tersebut terjadi karena kurangnya kewaspadaan dan kesiapan dalam menghadapi ancaman bahaya. Pengalaman yang terjadi secara berulang belum tentu meningkatkan kesiapsiagaan, perlu adanya sosialiasi dan pelatihan yang terintegrasi (Lesmana, Purborini, 2015).

Berdasarkan data laporan BPBD Lebak terjadi gempa bumi yang terjadi diwilayahlaut barat daya Kabupaten Lebak selas 23 Januari 2018. Pukul 13.35 WIB. Gempa dengan kekuatan 6,1 skala Richter. Kerusakan dilaporkan di 7 Kecamatan yaitu Kec. Sobang, Panggarangan, Wanasalam, Bayah, Cilongrang, Lebak Gedong dan Cimarga.Di Desa Sawarna sendiri ada 180 rumah yang mengalami rusak berat dan ringan akibat terjadinya gempa.

Ancaman bencana lingkungan selain gempa juga tsunami. sumber data dari BPBD Kabupaten Lebak enam kecamatan daeerah dipetakan berpotensi tsunami, karena berada diwilayah pertemuan (tumbukan) lempengan Samudera Hindia Australia- benua Asia.Keenam kecamatan tersebut yaitu Kecamatan Malingping, Wanasalam, Cihara, Panggarangan, Bayah, Cilongrang. Enam Kecamatan yang dipetakan rawan tsunami yang terletak di pesisir Samudera Hindia yaitu. Pantai Binuangeun, Bagedur, Suka Hujan, Panggarangan, Bayah, Pulau Manuk, Sawarna hingga Pelabuhan Ratu Sukabumi.

Ada 3 faktor yang mempengaruhi kesiapsiagaan yaitu pendidikan, pengetahuan dan pengalaman. Perlu adanya edukasi yang melibatkan semua masyarakat yang memiliki resiko tinggi 
terhadap bencana gempa bumi dan tsunami. Sawarna sebagai salah satu daerah wisata, merupakan daerah yang berpotensi terhadap bahaya gempa dan tsunami. Masyarakat yang tinggal disekitarnya perlu dilakukan edukasi.Salah satu lembaga yang berkepentingan dalam edukasi bencana yaitu sekolah.

Sekolah sebagai salah tempat yang belajar yang memberikan rasa aman dan nyaman dari gangguan seperti bencana. Sekolah sebagai satu agen perubahan diharapkan mampu menyebarluaskan informasi tentang bahaya lingkungan yang ada. Siswa sekolah dasar memerlukan informasi yang benar tentang bahaya tersebut. Ketidaktahuan akan bahaya gempa dan tsunami menyebabkan siswa tidak tahu bagaimana usaha untuk menyelamatkan diri. Oleh karena itulah diperlukan simulasi bagaimana usaha untuk menyelamatkan diri.

Warga sekolah belum dapat memahami tentang bahaya lingkungan yang mengancam sehingga memerlukan suatau ssosialisasi tentang jenis bahaya tersebut. Siswa sebagai sasaran kegiatan diharapakan dapat memiliki pengetahuan yang cukup, sikap yang sesuai dan ketrampilan yang cukup dalam rangka antisiapsi terhadap bencana yang ada. Siswa tidak memahami tentang jenis bahaya dikarenakan kurangnya media dan sarana untuk menyampaikan pada siswa dengan cara yang mudah murah dan efektif. Keterbatasan media dikarenakan kurangnya perhatian terhadap siswa alat/media yang menarik minat sesuai dengan karakter dari siswa. Sehingga perlu adanya kegaitan untuk meningkatkan kemampuan siswa SD di Sawarna dalam menghadapi bahaya gempa bumi dan tsunami.

\section{METODE PELAKSANAAN}

Usaha yang dilakukan dalam meningkatkan kemampuan siswa terhadap ancaman bencana dengan sosialisasi melalui media gambargambar dan kegiatan simulasi. Pelaksanaan melalui 3 tahapan, perencanaan, pelaksanaan dan evaluasi. Kegiatan dilakukan di SD 1 Sawarna Kecamatan Bayah Kabupaten Lebak Banten. Sekolah ini berada dalam zona merah yang sangat berbahaya jika terjadi bencana gempa bumi dan tsunami. Subyek dan sasaran adalah siswa kelas 3 di SD 1 Sawarna Kecamatan Bayah Kabupaten Lebak. Evaluasi kegiatan dengan melihat hasil pretest dan postest.

\section{HASIL DAN PEMBAHASAN}

Kegiatan dilaksanakan pada hari jumat tanggal 14 September 2019, Jam 09.00- selesai di Ruang kelas SD Sawarna 1 Kecamatan Bayah Kabupaten Lebak. Jumlah peserta 35 siswa terdiri dari 20 siswi dan 15 siswa dengan ratarata umur 8,7 tahun. Jarak lokasi kegiatan merupakan SD yang sangat dekat dengan pantai sehingga ketika terjadi tsunami akan berdampak langsung (zona merah).

Kegiatan pelaksanaan dibagi menjadi 2 sesi, yaitu penyampaian materi dan stimulasi sebelum dilakukan penyampaian materi dilakukan pretest untuk mengetahui sejauh mana siswa memahami tentang bencana. Setelah 
penyampaian materi dan stimulasi dilakukan postest untuk mengetahui sejauh mana pemahaman peserta setelah mendapatkan informasi yang benar tentang bencana. Penyampaian materi berisi pengenalan jenis bencana yang ada yaitu: gempa bumi, tsunami, tanah longsor, banjir, angin putting beliung/topan, kebakaran, gunung meletus. Pengenalan jenis bencana penting agar siswa mendapatkan pemahaman yang benar tentang jenis bencana yang ada. Materi berikutnya berupa lokasi-lokasi yang aman ketika bencana tersebut terjadi. Lokasi mana yang harus dituju dan dihindari (lapangan, rumah, gedung, pantai, dataran tinggi, pohon, sungai).

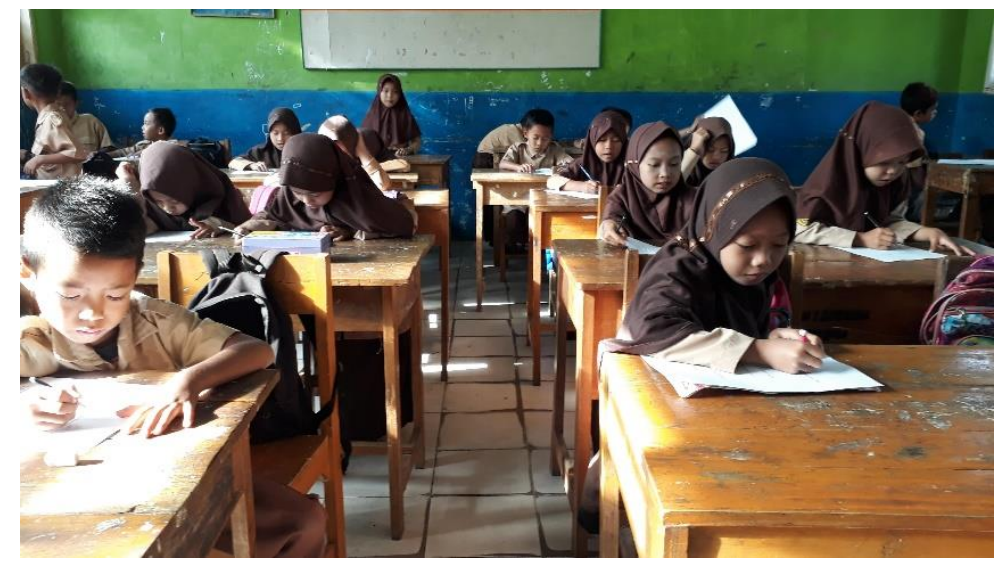

Gambar 1. Siswa sedangkan mengerjakan pretest sebelum acara dimulai (Sumber: Survey September, 2019)

Setelah disampaikan dengan materi kemudian dilakukan simulasi. Simulasi dilakukan dalam menghadapi bencana gempa bumi dengan menggunakan nyanyian. Siswa bernyanyi sambil memperagakan seperti melindungi kepala dengan menggunakan tas atau tangan, bersembunyi di bawah kolong meja, dan berlari secara tertib keluar menuju lapangan sekolah. Siswa sangat antusias mengikuti arahan dengan sambil bernyanyi. Beberapa yang lain berusaha untuk dapat berpartisipasi aktif dalam peragaan. Bernyanyi secara berulang-ulang diharapkan dapat memiliki memori yang lebih lama bagi siswa, sehingga akan dapat digunakan dikemudian hari. Bernyanyi yang disertai peragaan yang melibatkan gerak motoric akan dapat membantu dalam keterampilan yang dimiliki. Keterampilan dalam melindungi diri dari runtuhan benda-benda yang jatuh seperti tembok, kaca dengan berlindung pada kolong meja apabila berada pada ruangan. Lari menuju lapangan terbuka apabila memungkinkan untuk menghindari dari runtuhan benda-benda keras. 


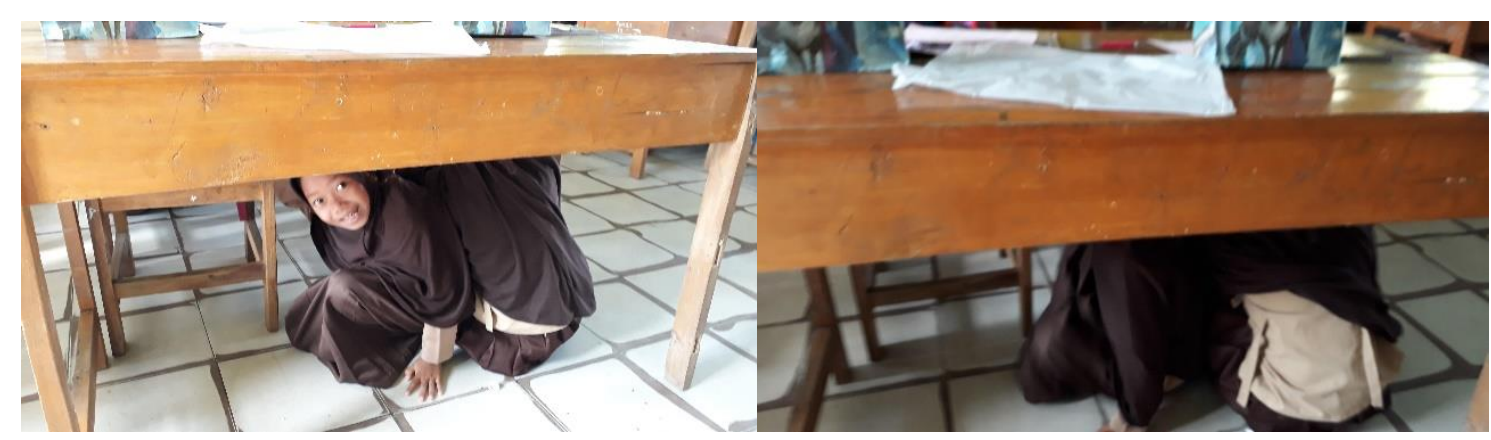

Gambar 2. Simulasi melindungi diri dibawah kolong meja

(Sumber: Survey September, 2019)

Mengetahui sejauh mana keberhasilan kegiatan dengan memberikan pretest dan postest kepada siswa dengan memberikan enam pertanyaan. Hasil jawaban pretest dari 34 siswa nilai terendah 25 sebanyak 9 siswa, nilai tertinggi 100 sebanyak 4 siswa, sisanya yang mendapatkan nilai 50 sebanyak 9 siswa dan 75 sebanyak 12 siswa.
Setelah dilakukan kegiatan sosialisasi, siswa diberikan postest untuk mengetahui sejauh mana sosialisasi dapat mencapai tujuan. Hasil jawaban postest dari 35 siswa nilai terendah 25 sebanyak 13 siswa, nilai tertinggi 100 sebanyak 10 siswa, sisanya yang mendapatkan nilai 50 sebanyak 3 siswa dan 75 sebanyak 9 siswa. Perbandingan hasil pretest dan postest dapat dilihat tabel berikut:

Tabel 1. Hasil Pre Test dan Post Test

\begin{tabular}{llll}
\hline No & Pertanyaan & pretes & postes \\
\hline 1 & $\begin{array}{l}\text { Bencana apa yang sudah pernah dirasakan } \\
\text { disekitar rumahmu }\end{array}$ & 350 & 420 \\
\hline 2 & $\begin{array}{l}\text { Apabila terjadi gempa bumi, anda akan } \\
\text { berlari kemana }\end{array}$ & 230 & 270 \\
\hline 3 & $\begin{array}{l}\text { Apabila terjadi tsunami, anda akan berlari } \\
\text { kemana }\end{array}$ & 270 \\
\hline 4 & $\begin{array}{l}\text { Apabila terjadi banjir, anda akan berlari } \\
\text { kemana }\end{array}$ & 130 \\
\hline 5 & $\begin{array}{l}\text { Apabila terjadi angin putting beliung akan } \\
\text { berlari kemana }\end{array}$ & 160 \\
\hline 6 & Apa tanda-tanda terjadi tsunami & 55 & 61 \\
\hline & Sumber: olah data 2019 &
\end{tabular}

Pertanyaan pertama jenis bencana yang pernah terjadi disekitar rumah hasil pretses menunjukan skor total 350, setelah dilakukan pelatihan skor menjadi
420. Adanya kenaikan 70 poin setelah dilakukan kegiatan penyampaian materi. Siswa dapat memahami bencana yang pernah terjadi disekitar rumah. Kenaikan 
poin menunjukan keberhasilan penyampaian materi tentang jenis bencana yang pernah terjadi yaitu gempa bumi, tsunami, gunung meletus. Pada postest jawaban bertambah yaitu gempa bumi, tsunami, gunung meletus, banjir, kebakaran, tanah longsor, puting beliung. Bertambahnya jawaban menunjukan siswa menyadari tentang berbagai macam bahaya yang kemungkinan terjadi diwilayah tempat tinggalnya.

Pertanyaan kedua berkaitan dengan lokasi yang aman jika terjadi gempa bumi. Hasil pretest menunjukan skor total 230, setelah dilakukan pelatihan skor menjadi 270. Adanya kenaikan 40 poin setelah dilakukan kegiatan penyampaian materi. Siswa dapat memahami tempat yang aman jika terjdi bencana gempa bumi. Tempat yang teraman ketika terjadi gempa bumi kelapangan terbuka, apabila dalam ruangan kelas ke kolong meja.

Pertanyaan ketiga apabila terjadi tsunami tempat yang paling aman Hasil pretest dan postest menunjukan skor total 270. Tidak adanya kenaikan point setelah dilakukan kegiatan penyampaian materi menunjukan kurang mengenanya metode yang disampaikan oleh tim. Perlu adanya terobosan dengan memaksimalkan berbagai media tayangan yang dapat meningkatkan pengetahuan siswa tentang wilayah yang aman ketika tsunami. Wilayah yang aman seperti dataran tinggi, gedung bertingkat, atau tempat-tempat yang memiliki ketinggian yang dapat terhindar dari gelombang tsunami. Perlu stimulasi juga ketempat, tempat tersebut.
Pada stimulasi yang dilakukan tim hanya ketika terjadi gempa bumi saja, mengingat disekitar sekolah tidak ditemukan bangunan/ tempat-tempat tinggi lainnya. Peningkatan pengetahuan dan keterampilan dalam penyelamatan diri dari tsunami ini penting mengingat ancaman terjadi tsunami sangat jelas bagi sekolah SD 1 Sawarna. Lokasi sangat dekat dengan bibir panatai, sehingga sangat berbahaya jika terjadi tsunami.

Pertanyaan keempat berkaitan dengan lokasi yang aman jika terjadi banjir. Hasil pretest menunjukan skor total 130, setelah dilakukan pelatihan skor menjadi 140. Adanya kenaikan 10 poin setelah dilakukan kegiatan penyampaian materi. Siswa dapat memahami tempat yang aman jika terjadi bencana banjir. Tempat yang teraman ketika terjadi banjir ke bangunan yang lebih tinggi.

Pertanyaan kelima berkaitan dengan lokasi untuk melarikan diri jika terjadi puting beliung Hasil pretest dan post tes menunjukan skor total 160 . Tidak adanya kenaikan point setelah dilakukan kegiatan penyampaian materi menunjukan kurang mengenanya metode yang disampaikan oleh tim. Perlu adanya terobosan dengan memaksimalkan berbagai media tayangan yang dapat meningkatkan pengetahuan siswa tentang wilayah yang aman ketika terjadi angin putting beliung. Wilayah yang aman ketika terjadi puting beliung seperti rumah. Perlu penjelasan dan pemaparan yang lebih dalam mengenai bencana ini agar siswa lebih memahamimya, tayangan 
animasi yang menarik perlu di sampaikan sehingga siswa benar-benar memahami tentang bahaya angin puting beliung.

Pertanyaan keenam esai berkaitan dengan tanda-tanda terjadinya tsunami. Hasil pretest menunjukan skor rata 55, setelah dilakukan pelatihan skor rata 61 . Adanya kenaikan rata-rata 6 poin setelah dilakukan kegiatan penyampaian materi. Sebelum dilakukan pelatihan siswa hanya menyebutkan ciri tsunami didahului oleh gempa saja. Setelah dilakukan pelatihan siswa dapat menyebutkan ciri-ciri terjadinya tsunami yaitu didahului oleh gempa dengan skala tertentu, adanya letusan gunung api, adanya surut air laut. Bertambahanya jumlah jawaban menunjukan keberhasilan penyampaian materi dalam menyebutkan ciri-ciri terjadinya tsunami.

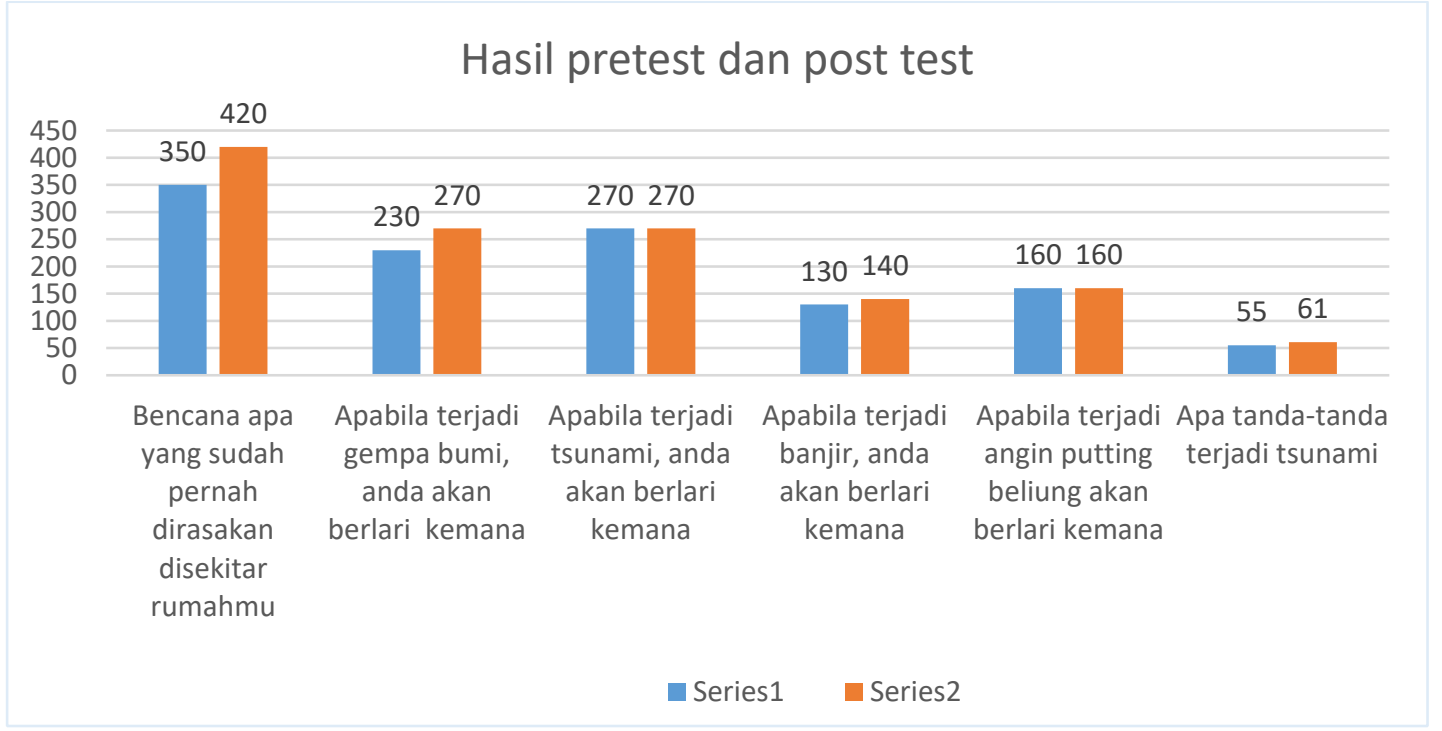

Gambar 4. Hasil pebandingan pretest dan postest pengetahuan bencana (Sumber Olah data, 2019)

Secara keseluruhan terjadi kenaikan pengetahuan dan pemahaman siswa diketahui dengan adanya kenaikan poin sebelum dilakukan kegiatan dan setelah dilakukan kegiatan. Pada pertanyaan yang tidak mengalami kenaikan poin hendaknya dapat ditindaklajuti dengan lebih menggalakan dalam bentuk-bentuk sosialisasi yang lain misalnya dalam kegiatan penyuluhan di masyarakat, guru dapat menyisipkan pada tema-tema tertentu yang diintegrasikan dalam kegiatan pembelajaran disekolah-sekolah. Guru dapat menganalisis kompetensi dasar pada tema-tema yang sudah ada dikurikulum, kemudian memberikan contoh yang kontekstual dengan masingmasing karekteristik wilayah dan bencana yang mengancamnya. Jenis bencana yang menurut Perka No 2 tahun 2012 yaitu: Gempa bumi, tsunami, banjir, tanah longsor, letusan gunung api, gelombang ekstrim dan abrasi, cuaca ekstrim, kekeringan, kebakaran hutan dan lahan, kebakaran gedung dan pemukiman, 
epidemi dan wabah penyakit, gagal teknologi dan konflik sosial. Dari ke tiga belas jenis bencana guru dapat memilih jenis bencana yang dapat mengancam daerah sekitarnya, sehingga lebih kontekstual. Wilayah kajian pantai selatan dengan memilih bencana yang terjadi yaitu gempa bumi, tsunami sehingga lebih kontekstual.

Secara umum dari hasil pretest, postest dan hasil stimulasi dapat berjalan sesuai dengan tujuan. Peserta yang merupakan siswa sekolah dasar kelas tiga sekolah dapat memahami jenis bencana, bencana yang mungkin terjadi dilingkungannya, dapat memahami tempat yang dituju ketika terjadi gempa, tsunami banjir dan puting beliung. Siswa dapat menyebutkan ciri-ciri terjadinya stunami. Seperti hasil penelitian dari Zahro, dkk indikator pengetahuan dasar tentang pengetahuan tsunami mencangkup aspek penyebab, gejala, ciri-ciri bangunan tahan tsunami. Siswa dapat mengikuti simulasi dengan sambil bernyanyi. Harapannya setelah mendapatkan pemahaman yang benar dapat ditularkan kepada temantemannya yang lain, maupun keluarga dan masyarakat pada umumnya.

Peningkatan pengetahuan siswa materi tentang kebencanaan juga dapat disisipkan pada RPP yang berhubungan dengan tema lingkungan sekitar, pada kegiatan ekstrakurikuler dapat melalui kegiatan pramuka (Rahmawati,F. N, 2016).

\section{PENUTUP}

Kegiatan pelaksanaan dibagi menjadi 2 sesi, yaitu penyampaian materi dan simulasi. Sebelum disampaikan materi dilakukan pretest, setelah setelah penyampaian materi diberikan postest. Penyampaian materi meliputi: penyampaian materi, memberikan kuis, permainan. Pemberian materi berkaitan dengan pengenalan jenis bencana yang ada yaitu: gempa bumi, tsunami, tanah longsor, banjir, angin putting beliung/topan, kebakaran, gunung meletus. Pengenalan jenis bencana penting agar siswa mendapatkan pemahaman yang benar tentang jenis bencana yang ada. materi selanjutnya tentang lokasi mana yang harus dituju dan dihindari (lapangan, rumah, gedung, pantai, dataran tinggi, pohon, sungai).

Secara umum dari hasil evaluasi dan hasil stimulasi dapat berjalan sesuai dengan tujuan. Peserta yang merupakan siswa sekolah dasar kelas tiga sekolah dapat memahami jenis bencana, bencana yang mungkin terjadi dilingkungannya, dapat memahami tempat yang dituju ketika terjadi gempa maupun tsunami. Siswa data menyebutkan ciri-ciri terjadinya tsunami. Siswa dapat mengikuti simulasi dengan sambil bernyanyi. Harapannya setelah mendapatkan pemahaman yang benar dapat ditularkan kepada temantemannya yang lain, maupun keluarga dan masyarakat pada umumnya.

Tidak adanya perubahan pada pertanyaan tentang tsunami diharapakan dapat membuat model dan strategi yang lain, siswa belum benar pemahaman tentang bencana tsunami. Perlu adanya sosialisasi yeng lebih luas kepada siswasiswa yang lain mengingat bahaya tsunami yang mengancam sekolah. Guru 
dapat menyisipkan pada tema-tema di mata pelajaran tertentu dan dapat melalui ekstrakulikuler seperti pramuka.

\section{DAFTAR PUSTAKA}

Bengen, D.G. 1999. Teknik Pengambilan Contoh dan Analisa Data Biofisik

Berwawasan Lingkungan. Direktorat Jenderal Pendidikan Tinggi, Departemen Pendidikan Nasional.

BNPB, 2017, Definisi dan Jenis bencana, http://www.bnpb.go.id

Diektorat Sumber Daya Mineral, Mitigasi Gempa Bumi dan PB. PGRI Yayasan Sampai Gempa Bumi dan Tsunami

Husein, Harun M .1995. Lingkungan Hidup, Masalah, Pengelolaan dan

Lembaga Penerbit Fakultas Ekonomi Universitas Indonesia, Volume 20, Nomor I.

Lesmana, Cindrawaty. Purborini, Nurul. 2015. Kesiapsiagaan Komunitas Sekolah dalam Menghadapi Bencana di Kabupaten Magelang. Jurnal Teknik Sipil, Vol 11 No 1 April 2015.
Tim Pengembang, Panduan Kurikulum Siaga Bencana SD, PUSKUR, 2008

Sumberdaya Pesisir. Pusat Kajian Sumberdaya Pesisir dan Lautan, Institut Pertanian Bogor.

Widianto, Bambang. 2000. Jurnal Lingkungan dan Pembangunan. Jakarta:

Rahmawati, Nur Faizah, 2016, Kesiapsiagaan Bencana Bumi pada Siswa SMP Siaga Bencana di Kabupaten Bantul (SMP Negeri 2 Imogiri)

Zahro, Zulfianty Rosyida. Anddriningrum. Hana, Sari. Elmawati Purnama. Gunawan, Imam. Sekolah Siaga Bencana: Kajian Evaluatif Kesiapsiagaan Sekolah Menghadapi Bencana. Seminar Nasional Pendidikan Fakultas Ilmu Pendidikan , Universitas Negeri Malang.

http://www.seis.nagoya-

u.ac.jp/sanchu/Seismo_Note/2007 /070912.jpg

http://news.bbc.co.uk/1/hi/world/41268 09.stm

http://en.wikipedia.org/wiki/2004_India n_Ocean_earthquake 